\title{
Factor Analysis for Entrepreneurial Development in Universities
}

\author{
Le Nguyen Doan Khoi* \\ Department of Scientific Affairs, Can Tho University, Vietnam
}

*Corresponding Author: Le Nguyen Doan Khoi, Department of Scientific Affairs, Can Tho University, Vietnam

\begin{abstract}
In this paper, we provide a concept of academic entrepreneurship created specifically to exploit technological knowledge originated within universities. This is the way to facilitate this transfer and to establish new enterprises with innovative knowledge and technologies as their strategic resource and competitive advantage. Moreover, spin-offs are probably the most visible form of commercialization of university research.
\end{abstract}

Keywords: academic entrepreneurship, technology transfer, entrepreneurial development

\section{INTRODUCTION}

The importance of university research in contributing to economic growth is today widely acknowledged in Vietnam (MOET, 2018). This has among other things led to that universities nowadays not only are expected to function as providers of human capital but also as growth engines to boost regional and national economies. The high expectation on universities to support research commercialization is especially evident in engineering, natural science and medical faculties as empirical evidence demonstrate a high rate of growth oriented ventures originating from these sources (Shane, 2004; Wright et al., 2008). As such, our study leans on the acknowledgement of the importance of technology transfer and knowledge diffusion from universities to the private sector for long term economic growth in national economies (Ardichvili et al., 2003).

In this article we aim to contribute to the emerging stream of research that have started to explore entrepreneurial activities in the pre-commercialization phase of university generated knowledge (e.g., Hindle and Yencken, 2004; Bercovitz and Feldman, 2008) by examining how prior entrepreneurial and private sector work experience influence university professors' ability to spot and seize potential business ideas in their research.

\section{LiTERATURE REVIEW}

Increased globalization and reduced basic funding are among the major changes that have influenced the emergence of a new "entrepreneurial" role of universities (Leslie and Slaughter, 1997, Burton, 1998). Universities are hence nowadays generally seen as potential contributors of innovation, job creation and technical change through university-industry collaborations and through their support of new knowledge-intensive start-ups (Chrisman, Hynes and Frasier, 1995; Etzkowiz and Leyesdorf, 1997; Feldman, 2000). As a result of these changes, universities are increasingly taking technology transfer and commercialization of research results as a part of their explicit mission due to pressures on universities to contribute to economic development and opportunities to gain personal wealth.

\subsection{Technology Transfer}

Technology transfer can occur either in an indirect or direct manner. Indirectly, research results can be applied and used in the commercial sector without formal contractual agreements between the university and users. Generally framed under the broad concept of "academic entrepreneurship", such activities include external teaching to individuals or organizations outside the university, consulting to solve specific problems, commercial sales of products developed within the university, and licensing of patents developed within the university. As such, compared to research-based education and publishing research results these latter activities are more deliberate attempts to increase individual or 
institutional profit, influence or prestige through the development, marketing and commercialization of research-based ideas or products (Louis et al., 1989).

\subsection{Research Commercialization}

Research commercialization cannot take place without prior discovery. This view is consistent with conceptual and empirical work in the entrepreneurship field where the entrepreneurial process start with the perception of opportunities for recombining resources on the market that someone believes will yield profit (Khoi, 2018).

University generated knowledge is not automatically transferred into the commercial domain and the main carriers of this knowledge in the very early phases of research commercialization are academics who are directly involved in its actual production. The high level of tacit knowledge inspiring research based business idea generation often entails that such novel insights initially are subjectively constituted and created in the minds of people (Hindle and Yencken, 2004). University professors are in this respect an important group of academics for the generation of business ideas that can be developed and commercially exploited.

An obvious prerequisite for the ability to generate research based business ideas is that professors have some time for research in their positions. A reasonable expectation may thus be that the more time for research the greater the likelihood of generating more research based business ideas. However, we conjecture that the time for research has a moderating effect on the relationship between prior entrepreneurial and private sector work experience and research based idea generation. In all, professors with more time for research in their positions can thus be expected to enhance the positive effect of prior entrepreneurial and private sector work experience on research based idea generation.

\section{Methodology}

We focused our study to one university to control for different university policies aimed at research commercialization (Rasmussen, Moen and Gullbrandsen, 2006). The choice fell on Can Tho University as it is one of the leading universities in Vietnam when it comes to the quality of research in areas such as education, science and technology. Moreover, the size and structure of the university offers the opportunity to get a satisfactory sample size with respect to the number of university professors working in these different faculties. In total, the university involves about 50,000 students and 1,200 staffs.

To meet the aim of the study we designed the empirical study as a questionnaire survey. The measures used in the questionnaire was derived from a careful review of previous theoretical and empirical work on academic entrepreneurship and public sector research commercialization (e.g., Louis et al., 1989; Bird, Hayward and Allen, 1993; Chrisman et al., 1995; Lee, 1996; Klofsten and Jones-Evans, 2000). The questions were pilot tested on a group of academics and based on this feedback the questions were honed and clarified for the final research instrument.

\section{Results}

Given that we have metric dependent variables and several metric or dichotomous independent variables we used linear multiple regression analysis for testing our hypotheses (Hair et al., 1998). Before introducing the variables in the regression models we carefully examined the data to detect problems of multicollinearity. All correlations between independent variables were below .70, and all VIF factors were also below the threshold levels suggested by Hair, Anderson, Tatham and Black (1998). This led us to suggest that there are no problems of multicollinearity in our data. A description of the variables used in the analysis (correlations, means and standard deviations) is displayed in Table 1.

Before making the analyses we carefully examined the data with respect to missing and uncompleted information. This examination led to that we ended up with a final sample of 90 cases with complete and accurate data for the variables of interest in our study. We are aware of the risk that smaller sample sizes can make statistical tests insensitive to real differences. Due to this we selected the .10 level as our overall threshold of significance in our analyses to avoid ignoring potentially important real differences.

We have hypotheses of both independent effects and interaction effects. An interaction effect exists if the interaction term gives a contribution over and above the independent effects model (Aiken and 
West, 1991; Cohen and Cohen, 1983). Therefore we introduced the variables stepwise to monitor the separate effects of our independent and interaction variables. First we entered the control, independent and moderator variables (step I). Then, we included the interaction variables (step II). The results from the regression analysis are presented in Table 1 below.

Table1: Regression analysis: research based business idea generation

\begin{tabular}{|l|l|l|l|}
\hline STEP & & Model 1 & \multicolumn{1}{|c|}{ Model 2 } \\
\hline I & Science faculty (control) & -.17 & -.17 \\
\hline & Technology faculty (control) & -.05 & -.10 \\
\hline & Age (control) & $-.24^{*}$ & $-.19+$ \\
\hline & Gender (control) & .07 & .00 \\
\hline & Foreign education (control) & -.01 & .03 \\
\hline & Percentage of research (moderator) & $.21+$ & $.18+$ \\
\hline & Start up experience (H1) & $.18+$ & $.20+$ \\
\hline II & Private sector work experience (H2) & $.32^{* *}$ & $.27^{*}$ \\
\hline & Start up experience x percentage of research (H3) & - & -.06 \\
\hline & Private sector work experience x percentage of research (H4) & - & $.29^{*}$ \\
\hline & $\mathrm{R}^{2}$ & .22 & .29 \\
\hline & $\Delta \mathrm{R}^{2}$ & - & $.07^{* *}$ \\
\hline & $\mathrm{F}($ F-sign) & $2.46^{*}$ & $2.66^{* *}$ \\
\hline
\end{tabular}

The table reports partial standardized coefficients (Beta), R-square and significance level $+<.10 *<.05, * *<.01$

The independent effects model is reported as step I in table 1 . Here we can observe that the regression models are significant, at $\mathrm{p}<.05$ and $\mathrm{p}<.01$ respectively. When it comes to hypothesis 1 and hypothesis 2 we can see that both these hypotheses are supported in model 1, although at different levels of significance. The positive association between prior entrepreneurial experience and a greater amount of research based business idea generation support $\mathrm{H} 1$ with a significant level of $\mathrm{p}<.10$. In a similar vein, the positive association between private sector work experience and a greater amount of research based business idea generation support $\mathrm{H} 2$ with a significant level of $\mathrm{p}<.01$.

The full model including interaction effects is reported as step II in table 2. As can be seen, the explained variance $\left(\mathrm{R}^{2}\right)$ increases from .22 to .27 and the increase is statistically significant at $\mathrm{p}<.01$, which suggests an interaction effect. At a closer look we can see that the interaction term for prior entrepreneurial experience in combination with increased time for research does not show any significant association. Instead, it is the interaction term for private sector work experience that in combination with increased time for research show a strong and positive association with research based idea generation.

\section{DISCUSSION AND CONCLUSION}

Technology transfer and commercialization of academic research, however, does not emerge and form spontaneously in response to formal policies and strategies but take place in response to the initial perceptions and activities of researchers who believe that their results may be commercially viable. Simply stated, a university - like any enterprise - will only be entrepreneurial if the people in it are behaving and acting like entrepreneurs. In response to this observation, we have in this study examined the validity of the "knowledge corridor thesis" (Ronstadt, 1988; Venkatamaran, 1997) within academia by analysing the influence of prior entrepreneurial and private sector experience on university professors' involvement in the very early stages of research commercialization. The result shows that both prior entrepreneurial experience and private industry experience significantly influence professors' ability to spot and generate business ideas based on their research. Moreover, we find support that the number of research based business ideas increase at a faster rate for professors with private sector work experience who also have more time for research in their positions. We will discuss these findings below in relation to their implications for theory and practice.

Activities aimed at research commercialization centers on an idea or a belief that must have been created and evaluated at some earlier point in time and thus, from a theoretical point of view, research commercialization cannot take place without prior business idea generation. We believe our focus on initial business idea generation is an important addition to contemporary theory and research on academic entrepreneurship since all new economic activity initially starts as ideas for new business (Hindle and Yencken, 2004). As such, our findings contribute to the small but growing body of knowledge informing about entrepreneurial activities in the pre-commercialization phase of university 
generated knowledge (e.g., Bird, et al., 1993; Hindle and Yencken, 2004; Bercovitz and Feldman, 2008). Moreover, although previous research has examined individual characteristics and personal attributes among university scholars the issue of work experience from outside the academic sector has not been explicitly studied. This despite continuing debates about the need to support intersectorial mobility of experienced researchers between academia and private industry. We have in this respect provided novel empirical evidence showing how experience from the private sector may influence technology transfer and commercialization of research results within academia.

In summary, we found the significant associations between both prior entrepreneurial and private sector work experience and research based business idea generation, the latter relationship being particularly strong. In addition, we find that professors who have high private sector work experience have a significantly higher research based idea generation if they also have a high amount of time for research in their positions. These results are largely in favor of our theoretical expectations and consequently support the validity of the knowledge corridor thesis in academic environments, suggesting that when university professors' gain entrepreneurial and private sector experience this set them off a journey down a corridor through which windows of opportunity will open up around them.

\section{REFERENCES}

[1] Ardichvili, A., Cardozo, R., and Ray, S. (2003) A theory of entrepreneurial opportunity identification and development, Journal of Business Venturing, 18(1), 105-123.

[2] Bercovitz, J. and Feldman, M. (2008) Academic Entrepreneurs: Organizational Change at the Individual Level, Organization Science, 19(1), 69-89,184-185.

[3] Breschi, S., Lissoni, F. and Montobbio, F. (2008) University patenting and scientific productivity: a quantitative study of Italian academic inventors, European Management Review, 5(2), 91-110.

[4] Burnside, B. and Witkin, L. (2008) Forging successful university-industry collaborations, Research Technology Management, 51(2), 26-30.

[5] Chrisman, J. J., Hynes, T., and Fraser, S. (1995) Faculty entrepreneurship and economic development - the case of the University-of-Calgary, Journal of Business Venturing, 10, 267-281.

[6] Hair, J.F., Anderson, R.E., Tatham, R.L., and Black, W.C (1998) Multivariate data analysis (fifth edition), New Jersey: Prentice Hall.

[7] Khoi, L.N.D. (2018), The solutions for enhancing the product commercialization through cooperation between entrepreneurship with universities, International Journal of Scientific Research, 452-454

[8] Klofsten, M. (2005) New venture ideas: an analysis of their origin and early development, Technology Analysis and Strategic Management, 17(1), 105-119.

[9] Lee, Y. S. (1996) Technology transfer' and the research university: A search for the boundaries of university-industry collaboration, Research Policy, 25, 843-863.

[10] Parks, J. (2005) Opportunity recognition and product innovation in entrepreneurial hi-tech start-ups: a new perspective and supporting case study, Technovation, 25(7), 739-752.

\section{AUTHORS' BIOGRAPHY}

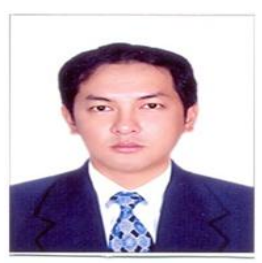

Assoc.Prof. Dr. Le Nguyen Doan Khoi is working as the Vice Director of Scientific Research Affairs Department in Can Tho University. He graduated PhD from the University of Groningen, the Netherlands in Business and Innovation. His research focuses on supply chain management, business strategic management for SMEs, and start-up business eco-system development in the University.

Citation: Le Nguyen Doan Khoi. "Factor Analysis for Entrepreneurial Development in Universities" International Journal of Managerial Studies and Research (IJMSR), vol 7, no.11, 2019, pp. 1-4. doi: http://dx. doi.org/10.20431/2349-0349.0711001.

Copyright: (C) 2019 Authors. This is an open-access article distributed under the terms of the Creative Commons Attribution License, which permits unrestricted use, distribution, and reproduction in any medium, provided the original author and source are credited. 